\title{
Gambaran Karakteristik dan Motivasi Tim Nusantara Sehat: Hasil Monitoring dan Evaluasi Periode 1 dan 2
}

\author{
Characteristic and Motivation of Nusantara Sehat Team Based: Based on \\ Monitoring and Evaluation of First and Second Batch
}

\author{
Mieska Despitasari ${ }^{1}$, Nita Prihartini ${ }^{1}$, dan Harimat Hendarwan ${ }^{1}$ \\ 1) Pusat Penelitian dan Pengembangan Sumber Daya dan Pelayanan Kesehatan, Jalan Percetakan Negara No. 29 Jakarta \\ 10560, Indonesia \\ Korespondensi: mieska.litbang@gmail.com
}

Submitted: 22 Oktober 2018, Revised: 12 November 2018, Accepted: 30 November 2018

https://doi.org/10.22435/jpppk.v2i3.639

\begin{abstract}
Abstrak
Nusantara Sehat (NS) adalah salah satu program yang mendukung fokus kebijakan Kementerian Kesehatan periode 2015-2019 terkait pelayanan kesehatan (yankes) primer, termasuk mendukung program Jaminan Kesehatan Nasional (JKN). Diharapkan melalui program NS, dapat terjadi peningkatan akses dan kualitas yankes di Daerah Terpencil, Perbatasan dan Kepulauan (DTPK). Program NS dilakukan dengan penempatan tenaga kesehatan (nakes) berbasis tim yang terdiri dari beberapa jenis nakes pada tahun 2015 yang terbagi ke dalam dua periode. Penelitian ini bertujuan mengetahui gambaran karakteristik dan motivasi tenaga Nusantara Sehat periode 1 dan 2 sebagai salah satu komponen pemberi layanan di DTPK. Penelitian dengan studi kuantitatif yang didesain potong lintang. Data dikumpulkan dengan menggunakan kuesioner yang dijawab oleh 690 responden NS. Data dianalisis dengan deskriptif. Jenis nakes dengan proporsi di atas $15 \%$ adalah tenaga kesehatan lingkungan, bidan, tenaga kesehatan masyarakat, tenaga gizi dan perawat. Tenaga dokter menempati proporsi terkecil. Sebagian besar berpendidikan terakhir diploma III. Kurang dari $30 \%$ yang berjenis kelamin laki-laki. Responden terbanyak berusia 20-24 tahun. Berdasarkan perhitungan skor motivasi Alderfer, tidak ada satupun responden yang masuk ke dalam kategori motivasi rendah. Hampir $92 \%$ responden memiliki motivasi tinggi dan berbeda bermakna untuk variabel usia dengan $p$-value $=0,036$ $(p<0,05)$. Walaupun responden berasal dari berbagai periode keberangkatan, jenis tenaga, tingkat pendidikan terakhir, jenis kelamin dan kemiripan wilayah geografis, tidak ada perbedaan skor motivasi antar kelompok. Peningkatan penyebaran informasi pendaftaran sehingga lebih luas dapat dilakukan dengan memperpanjang tenggat waktu terjangkau oleh seluruh masyarakat Indonesia dan menumbuhkan minat untuk mendaftar menjadi tenaga Nusantara Sehat.
\end{abstract}

Kata kunci: motivasi nakes, DTPK, nusantara sehat

\section{Abstract}

Nusantara Sehat (NS) is one of the programs that supports the Ministry of Health's policy focus for the 20152019 period regarding primary health care, including supporting the National Health Insurance (JKN) program. It is expected that through the NS program, there will be an increase in access and quality of services in remote areas, borders and islands (DTPK). The NS program is conducted by placing team-based health workers consisting of several types of health workers in 2015 divided into two periods. This study aims to describe characteristics and motivation of Nusantara Sehat batch 1 and 2 as one of service provider component in Indonesia's remote areas (DTPK). Data was obtained by filling out a quantitative questionnaire by 690 respondents. 555 respondents were filling out a questionnaire. The study used cross sectional design and the data is processed descriptively. Environmental health workers, midwives, public health personnel, nutritionist and nurses were types of personnel with more than 15\% proportions. Doctors occupy the smallest proportion. 
Most recently educated diploma III. Less than 30\% are male. Most respondents aged 20-24 years. Based on the calculation of Alderfer motivation score, none of the respondents were low motivated. Almost 92\% of respondents have high motivation and are significantly different for age variables with $p$-value $=0.036$ ( $p$ $<0.05)$. Although respondents came from various periods of departure, type of staff, recent education level, gender and similarity in geographical area, there were no differences in motivation scores between groups. To increase the widespread distribution of registration information and longer deadlines so that it is affordable for all Indonesian people and foster interest in registering as a Nusantara Sehat staff.

Keywords: health worker motivation, remote areas, nusantara sehat

\section{Pendahuluan}

Nusantara Sehat (NS) adalah salah satu program yang mendukung fokus kebijakan Kementerian Kesehatan periode 2015-2019 terkait pelayanan kesehatan (yankes) primer, termasuk mendukung program Jaminan Kesehatan Nasional (JKN). Program NS diharapkan dapat meningkatkan akses dan kualitas yankes di Daerah Terpencil, Perbatasan dan Kepulauan (DTPK), melalui penempatan tenaga kesehatan (nakes) berbasis tim yang terdiri dari beberapa jenis nakes pada tahun 2015 yang terbagi ke dalam dua periode. Pada periode pertama ditempatkan 142 orang di 20 puskesmas dan pada periode kedua ditempatkan 552 orang nakes di 100 puskesmas. ${ }^{1}$ Hingga Mei 2017, telah ditempatkan 1.769 nakes di 311 puskesmas. Setiap tim terdiri dari 5-7 orang anggota tim dari berbagai profesi dari 9 jenis profesi nakes. Setiap akan ditugaskan selama 2 tahun di puskesmas penugasan yang telah ditentukan sebagai lokus melalui verifikasi. Beberapa lokus setelah dilakukan evaluasi masih memenuhi syarat untuk ditempatkan kembali tim NS. ${ }^{2}$

Nakes didefinisikan sebagai orang yang mengabdikan diri di bidang kesehatan serta memiliki pengetahuan dan/atau keterampilan melalui pendidikan di bidang kesehatan yang untuk jenis tertentu memerlukan kewenangan untuk melakukan upaya kesehatan. ${ }^{3}$ DTPK sebagai lokus NS memiliki tantangan dan karakteristik tersendiri yang berbeda dengan kondisi daerah non-DTPK akibat kondisi geografis yang sulit dijangkau, sarana prasarana dan sumber daya manusia yang terbatas. ${ }^{4}$ Motivasi nakes sangat menentukan retensi dalam penugasan di DTPK. Sikap mental karyawan yang positif terhadap situasi kerja dapat memperkuat motivasi kerja. ${ }^{5}$

Motivasi adalah kondisi mental yang mendorong dilakukannya suatu tindakan (action atau activities) dan memberikan kekuatan yang mengarah kepada pencapaian kebutuhan, memberi kepuasan, mengurangi ketidakseimbangan ataupun pencapaian tujuan organisasi perusahaan. ${ }^{5}$

Tulisan ini bertujuan untuk mengetahui gambaran karakteristik dan motivasi tenaga Nusantara Sehat periode 1 dan 2 sebagai salah satu komponen pemberi layanan di DTPK.

\section{Metode}

Penelitian dengan studi kuantitatif yang didesain potong lintang. Pengumpulan data diperoleh dengan menggunakan kuesioner yang dijawab oleh tenaga NS yang terdiri dari dokter, bidan, tenaga keperawatan, tenaga kesehatan masyarakat, tenaga gizi, tenaga kefarmasian, tenaga kesehatan lingkungan dan tenaga analis kesehatan. Responden adalah tenaga NS periode I dan II sebanyak 690 nakes. Tenaga NS periode I dan II sebelum berakhir masa penugasan di puskesmas selama 2 tahun diundang ke Jakarta pada bulan Desember 2016. Data yang terkumpul dan diolah sebanyak 555 kuesioner sebab sebanyak 135 kuesioner tidak dianalisis karena tidak lengkap. Tujuan penelitian adalah untuk mengetahui gambaran karakteristik dan motivasi nakes NS. Karakteristik yang dianalisis adalah jenis kelamin, batch NS, usia, jenis tenaga, pendidikan terakhir, dan kemiripan regional geografis di mana tenaga NS ditempatkan.

Motivasi NS dapat diketahui dengan melakukan penilaian berdasarkan Teori Alderfer yaitu faktor hubungan, pertumbuhan, dan keberadaan. ${ }^{8}$ Skor faktor hubungan diperoleh dari skoring pertanyaan dukungan tim, dukungan puskesmas, dan adaptasi di mana ketiga variabel diberikan bobot yang sama. Skor faktor pertumbuhan merupakan hasil skoring dari variabel harapan untuk menjadi CPNS pusat, CPNS daerah, honorer, dan 
harapan untuk memperoleh beasiswa. Sementara skor kehidupan merupakan skor dari variabel imbalan/gaji. Skor motivasi dihitung dengan menjumlahkan skor faktor hubungan, pertumbuhan, dan kehidupan. Skor kemudian dikategorikan menjadi 3 kelompok skor dengan range yang sama. Pengolahan data dilakukan dengan menggunakan perangkat komputer, uji yang digunakan adalah uji Kruskall-Wallis dan Mann-Whitney, untuk melihat perbedaan rerata skor motivasi antarkelompok dengan karakteristik yang berbeda. Penelitian ini mendapat persetujuan Etik dengan nomor : LB.02.01/5.2/KE.278/2016.

\section{Hasil}

Berdasarkan analisis data diperoleh hasil jenis tenaga dengan proporsi di atas $15 \%$ adalah tenaga kesehatan lingkungan, bidan, tenaga kesehatan masyarakat, tenaga gizi dan perawat. Tenaga dokter menempati proporsi terkecil dari seluruh responden. $69,9 \%$ berpendidikan terakhir diploma III dan terendah, 4,9\% responden dengan pendidikan terakhir diploma IV. Kurang dari 30\% tenaga tersebut yang berjenis kelamin laki-laki. Hasil perhitungan skor motivasi Alderfer, ${ }^{6}$ tidak ada satupun responden yang masuk ke dalam kategori dengan motivasi rendah. Hasil analisis menunjukkan bahwa 91,4\% responden memiliki motivasi tinggi (Tabel 1). Usia responden antara 2031 tahun, dengan responden terbanyak berusia 2324 tahun (Gambar 1).

Untuk mengetahui karakteristik tenaga NS yang mempengaruhi motivasi, digunakan uji beda mean. Hasil uji normalitas menunjukkan bahwa data

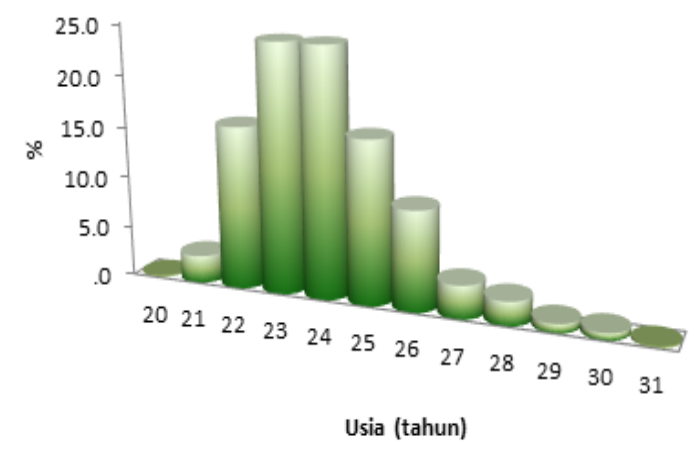
Gambar 1. Proporsi Responden Berdasarkan
Usia skor motivasi tidak terdistribusi normal, sehingga uji yang digunakan adalah uji Kruskall-Wallis dan Mann-Whitney. Hasil uji terhadap skor motivasi Alderfer berdasarkan batch NS, jenis tenaga, tingkat pendidikan terakhir, jenis kelamin, usia dan kemiripan wilayah geografis menunjukkan hasil yang dapat dilihat pada Tabel 2 .

\section{Pembahasan}

Tim Nusantara Sehat (team based) ditugaskan untuk memenuhi kebutuhan dari sisi jumlah, jenis dan kualifikasi tenaga kesehatan di puskesmas DTPK. Tim tersebut terdiri dari 5 jenis tenaga kesehatan yaitu dokter, perawat, bidan, dan 2 jenis tenaga kesehatan lainnya (dokter gigi, tenaga gizi, tenaga kesehatan lingkungan, ahli teknologi laboratorium medik, tenaga kefarmasian dan tenaga

Tabel 1. Karakteristik Responden Penelitian Evaluasi Penugasan Khusus Tenaga Kesehatan Berbasis Tim (Team Based) $\mathrm{n}=\mathbf{5 5 5}$

\begin{tabular}{|c|c|c|}
\hline No & Karakteristik & $\%$ \\
\hline \multirow[t]{9}{*}{1.} & Jenis Ketenagaan & \\
\hline & - Tenaga Kesehatan Lingkungan & 17,3 \\
\hline & - Bidan & 16,9 \\
\hline & - Tenaga Kesehatan Masyarakat & 16,2 \\
\hline & - Tenaga Gizi & 15,9 \\
\hline & - Tenaga Keperawatan & 13,3 \\
\hline & - Tenaga Analis Kesehatan & 11,9 \\
\hline & - Tenaga Farmasi & 7,0 \\
\hline & - Dokter Umum & 1,4 \\
\hline \multirow[t]{5}{*}{2.} & Jenjang Pendidikan Terakhir & \\
\hline & - Diploma III & 69,9 \\
\hline & - Strata I & 17,8 \\
\hline & - Strata I + Profesi dan Strata II & 7,4 \\
\hline & - Diploma IV & 4,9 \\
\hline \multirow[t]{3}{*}{3.} & Jenis Kelamin & \\
\hline & - Perempuan & 71,4 \\
\hline & - Laki-laki & 28,6 \\
\hline \multirow[t]{4}{*}{4.} & Kategori Skor Motivasi Alderfer & \\
\hline & - Tinggi & 91,4 \\
\hline & - Sedang & 8,6 \\
\hline & - Rendah & 0,0 \\
\hline
\end{tabular}


Tabel 2. Hasil Uji Beda Mean Variabel Skor Motivasi Alderfer

\begin{tabular}{|c|c|c|c|c|c|c|}
\hline No & Karakteristik Pembeda & Jenis Uji & $\mathbf{n}$ & $\begin{array}{l}\text { Mean } \\
\text { Rank }\end{array}$ & $\mathbf{p}$ & Kesimpulan \\
\hline \multirow[t]{3}{*}{1.} & Jenis Kelamin & Mann-Whitney & & & 0,299 & \multirow{3}{*}{ Tidak ada perbedaan mean } \\
\hline & - Laki-laki & & 159 & 266,84 & & \\
\hline & - Perempuan & & 396 & 281,48 & & \\
\hline \multirow[t]{3}{*}{2.} & Batch (Periode Keberangkatan) & Mann-Whitney & & & 0,667 & \multirow{3}{*}{ Tidak ada perbedaan mean } \\
\hline & - Batch 1 & & 115 & 272.27 & & \\
\hline & - Batch 2 & & 440 & 279.5 & & \\
\hline \multirow[t]{4}{*}{3.} & Usia & Kruskall-Wallis & & & 0,036 & \multirow{4}{*}{ Ada perbedaan mean } \\
\hline & - 20-24 tahun & & 372 & 290.27 & & \\
\hline & - 25-29 tahun & & 178 & 253.44 & & \\
\hline & $->29$ tahun & & 5 & 239.3 & & \\
\hline \multirow[t]{9}{*}{4.} & Jenis Tenaga & Kruskall-Wallis & & & 0,753 & \multirow{9}{*}{ Tidak ada perbedaan mean } \\
\hline & - Gizi & & 88 & 290.61 & & \\
\hline & - Analis Kesehatan (Lab) & & 66 & 280.13 & & \\
\hline & - Farmasi & & 39 & 289.06 & & \\
\hline & - Bidan & & 94 & 268.11 & & \\
\hline & - Dokter Umum & & 8 & 183.94 & & \\
\hline & - Perawat & & 74 & 271.42 & & \\
\hline & - Kesehatan Lingkungan & & 96 & 275.51 & & \\
\hline & - Kesehatan Masyarakat & & 90 & 286.07 & & \\
\hline \multirow[t]{5}{*}{5.} & Pendidikan Terakhir & Kruskall-Wallis & & & 0,145 & \multirow{5}{*}{ Tidak ada perbedaan mean } \\
\hline & - S1 + Profesi & & 41 & 227.88 & & \\
\hline & $-\mathrm{S} 1$ & & 99 & 287.05 & & \\
\hline & - D-IV & & 27 & 251.63 & & \\
\hline & - D-III & & 388 & 282.82 & & \\
\hline \multirow[t]{4}{*}{6.} & Kemiripan Regional Geografis & Kruskall-Wallis & & & 0,208 & \multirow{4}{*}{ Tidak ada perbedaan mean } \\
\hline & - Sumatera, Jawa, Bali & & 80 & 302.98 & & \\
\hline & - Sulawesi, Kalimantan, NTB & & 192 & 282.14 & & \\
\hline & - NTT, Maluku, Papua & & 283 & 268.13 & & \\
\hline
\end{tabular}

kesehatan masyarakat). ${ }^{7}$ Jenis tenaga Nusantara Sehat batch 1 dan 2 dengan proporsi terbanyak adalah tenaga kesehatan lingkungan, bidan, tenaga kesehatan masyarakat, tenaga gizi dan perawat, sedangkan tenaga dokter menempati proporsi terkecil dari seluruh responden. Penelitian lain dengan responden tim Nusantara Sehat menunjukkan bahwa terdapat hubungan negatif antara tingkat pendidikan dengan komitmen organisasi tenaga kesehatan penugasan khusus di DTPK. ${ }^{7}$
Banyaknya responden berpendidikan terakhir diploma III dan paling sedikit responden dengan pendidikan terakhir diploma IV yang menjadi NS adalah berkaitan dengan peminat yang mendaftar menjadi NS di mana peminat yang paling banyak untuk mengikuti NS adalah alumni diploma III (Tabel 1). Beberapa jenis tenaga kesehatan Nusantara Sehat merupakan lulusan yang terdiri dari berbagai jenjang pendidikan untuk satu jenis tenaga kesehatan. Contohnya perawat yang terdiri 


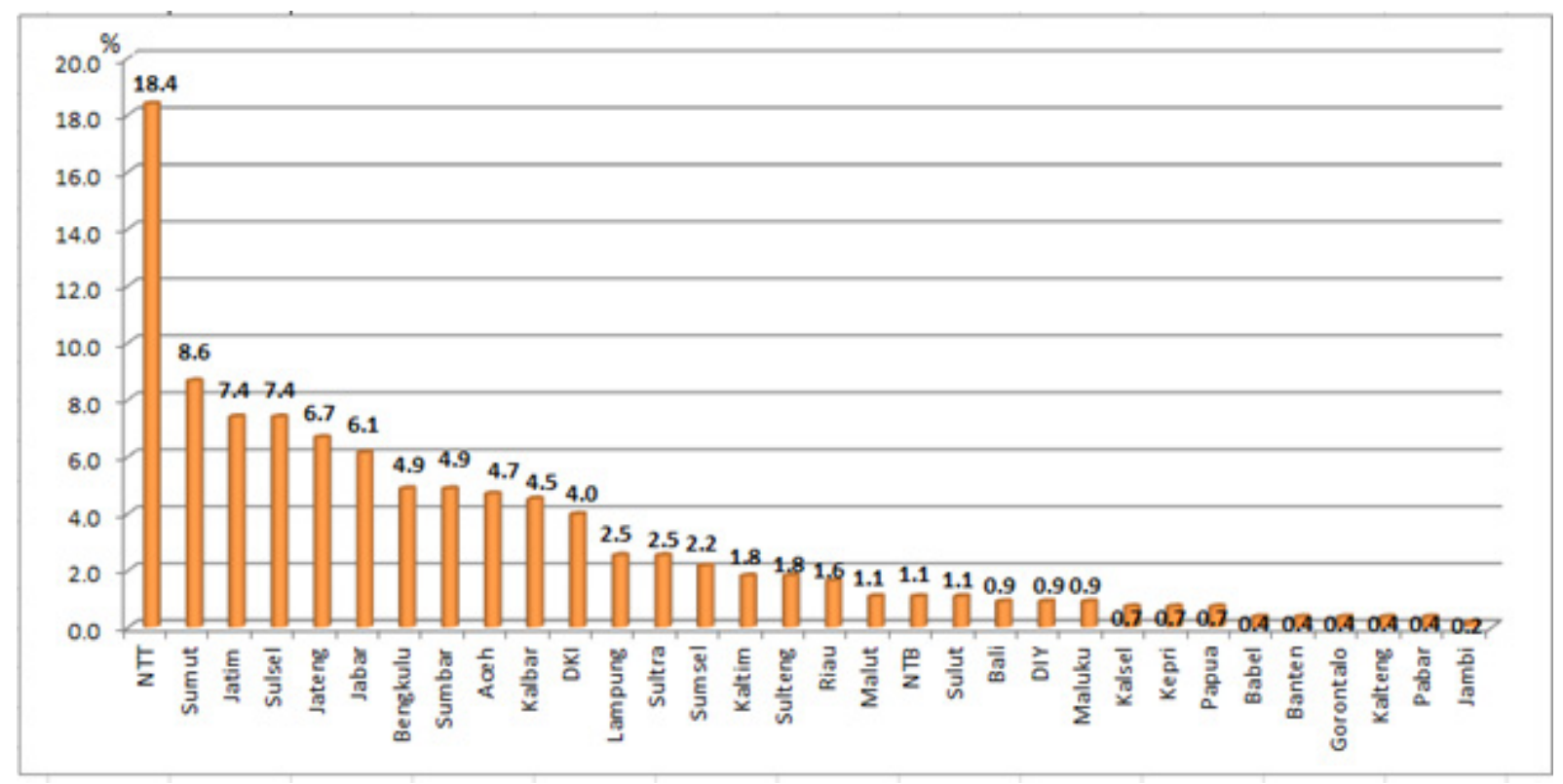

\section{Gambar 2. Proporsi responden berdasarkan asal daerah}

dari lulusan DIII keperawatan, DIV keperawatan, S1 keperawatan dan S1 perawat profesi (Ners). Sementara pekerjaan mereka di lapangan tidak jauh berbeda. Karyawan dengan pendidikan yang lebih tinggi memiliki harapan yang lebih tinggi apabila dibandingkan dengan rekan kerjanya yang berpendidikan lebih rendah. Hal tersebut dalam hirarki kebutuhan Maslow, sudah mengarah pada kebutuhan aktualisasi diri. ${ }^{7}$

Kurang dari $30 \%$ responden berjenis kelamin laki-laki (Tabel 1). Responden berusia antara 20-31 tahun, dengan responden terbanyak berusia 23-24 tahun (Gambar 1). Rentang umur tersebut merupakan tahap Trial with Commitment di mana individu sudah merasa nyaman dengan pekerjaannya sehingga akan terus mempertahankannya, sedangkan umur di bawah 2520 tahun cenderung masih dalam taraf pencarian jati diri sehingga komitmennya cukup rendah. ${ }^{7}$ Tenaga Nusantara Sehat yang menjadi responden berasal dari seluruh provinsi di Indonesia kecuali Sulawesi Barat dan Kalimantan Utara. Responden tenaga Nusantara Sehat terbanyak berasal dari Provinsi Nusa Tenggara Timur dan tersedikit dari provinsi Jambi (Gambar 2).

Setelah dilakukan perhitungan skor motivasi Alderfer, tidak ada satupun responden yang masuk ke dalam kategori motivasi rendah. Sebagian besar responden memiliki motivasi tinggi.
Teori Alderfer mengungkapkan bahwa terdapat 3 kategori kebutuhan manusia yang perlu dipenuhi sebagai sumber motivasi kerja yaitu:

a. Kebutuhan akan keberadaan (Existence Needs). Kebutuhan ini mencakup hal-hal yang berhubungan dengan kebutuhan dasar/ material, fisiologis, psikologis dan rasa aman. Contohnya makan, minum, udara, pakaian, keamanan, fisik, cinta dan kasih sayang. Kebutuhan ini merupakan gabungan dari level 1 dan 2 hierarki Maslow.

b. Kebutuhan akan hubungan (Relatedness Needs), yang terdiri dari penghargaan sosial dan eksternal. Kebutuhan ini menekankan urgensi hubungan antar-individu (interpersonal relationship) dan bermasyarakat (social relationship). Pengakuan dan perasaan aman sebagai bagian dari kelompok atau keluarga. Kebutuhan ini merupakan gabungan dari level 3 dan 4 hierarki Maslow.

c. Kebutuhan akan pertumbuhan (Growth Needs), yang terdiri dari penghargaan internal dan aktualisasi diri. Kebutuhan ini mencakup keinginan intrinsik dalam diri seseorang untuk maju atau meningkatkan kemampuan pribadinya. Kebutuhan ini berdampak terhadap kreativitas dan produktivitas diri dan lingkungannya. Kebutuhan ini merupakan gabungan dari level 4 dan 5 hierarki Maslow. ${ }^{6,8,9}$

Sebagian besar responden memiliki motivasi kerja yang tinggi menurut Alderfer. Hal 
ini dapat mencerminkan hal yang sesungguhnya atau dapat juga merupakan bias yang terjadi akibat pengumpulan data yang dilaksanakan menjelang berakhirnya masa tugas tim Nusantara Sehat periode 1 dan 2.

Tidak ada perbedaan skor motivasi Alderfer antar periode keberangkatan (batch NS), jenis tenaga, tingkat pendidikan terakhir, jenis kelamin dan kemiripan wilayah geografis. Dan ada perbedaan yang bermakna untuk variabel usia dengan $\mathrm{p}$-value= $0,036(p<0,05)$. Hal ini sejalan dengan penelitian lain bahwa tenaga kesehatan berusia kurang dari 30 tahun mempunyai motivasi kerja yang tinggi dan tidak ada hubungan yang signifikan antara motivasi dan jenis kelamin. ${ }^{10,11}$

Hasil penelitian menunjukkan bahwa tidak ada perbedaan antara jenis kelamin dan motivasi sehingga dalam perekrutan NS tidak perlu ada pembedaan proporsi antara pelamar laki-laki dan perempuan. Namun, pertimbangan jenis kelamin perlu dilakukan terkait dengan medan tugas tim NS meskipun pertimbangan geografis tidak akan mempengaruhi motivasi.

\section{Kesimpulan}

Tim Nusantara Sehat Batch 1 dan 2 proporsi terbanyak tenaga kesehatan lingkungan, bidan, tenaga kesehatan masyarakat, tenaga Gizi dan perawat. Dengan usia responden terbanyak 23-24 tahun dan kurang dari 30\% berjenis kelamin laki-laki. Responden dari Sulawesi Barat dan Kalimantan Utara pada periode ini belum ada. Responden terbanyak dari Provinsi Nusa Tenggara Timur dan tersedikit dari Provinsi Jambi. Sebagian besar responden memiliki motivasi tinggi. Walaupun responden berasal dari berbagai periode keberangkatan, jenis tenaga, tingkat pendidikan terakhir, jenis kelamin dan kemiripan wilayah geografis, tidak ada perbedaan skor motivasi antar kelompok.

\section{Saran}

Peningkatan penyebaran informasi pendaftaran yang meluas dan tenggat waktu yang lebih panjang disarankan agar Provinsi yang tidak mempunyai tenaga Nusantara Sehat karena keterbatasan waktu dan informasi dapat terakomodasi, sehingga terjangkau oleh seluruh tenaga kesehatan di Indonesia dan menumbuhkan minat untuk mendaftar sebagai tenaga Nusantara Sehat. Pengukuran tingkat motivasi sebaiknya dilakukan di awal penempatan agar tidak terjadi bias pengukuran.

\section{Ucapan Terima Kasih}

Terima kasih disampaikan untuk tenaga Nusantara Sehat batch 1 dan 2 sebagai responden, serta para peneliti sebagai pendamping yang telah membantu pengumpulan data motivasi pada saat monitoring dan evaluasi Nusantara Sehat.

\section{Daftar Rujukan}

1. www.nusantarasehat.kemkes.go.id/content/ sekilas-nusantara-sehat. Diakses 3 Juli 2018 pukul 10:12.

2. http://www.depkes.go.id/article/ view/17053000005/tugas-tim-nusantara-sehatbatch-i-berakhir.html. Diakses 3 Juli 2018 pukul 13:55.

3. Undang-Undang No. 36 tahun 2014 tentang Tenaga Kesehatan.

4. Wiyanti S. Pola Pemanfaatan Pelayanan Kesehatan Daerah Tertinggal, Perbatasan, Kepulauan dan Terpencil (DTPK-T) di Indonesia (Analisis Data Riskesdas 2013). Tesis Program Pascasarjana Universitas Gajahmada. 2016.

5. Mangkunegara AP, Prabu A. Evaluasi kinerja sumber daya manusia. Bandung: Refika Aditama. 2005

6. Robbins SP, Judge TA. Perilaku Organisasi. Salemba Empat. Jakarta. 2008.

7. Badarianto D, Pardede FD. Karakteristik Personal dan Kepuasan Kerja dengan Komitmen Keorganisasian Tenaga Kesehatan di Daerah Tertinggal Perbatasan dan Kepulauan Indonesia. Jurnal Ekologi Kesehatan. 2017. 16(3): h:170 182.

8. Kristinae V. Analisis Pengaruh Motivasi Kerja dan Lingkungan Kerja terhadap Kepuasan Kerja (Studi Kasus pada Karyawan di Pujasera Palangka Raya). Jurnal Aplikasi Manajemen, Ekonomi dan Bisnis. 2018. 2(2): h:78-93.

9. Ball B. A summary of motivation theories. https://www.yourcoach.be/blog/wp-content/ uploads/2012/03/A-summary-of-motivationtheories1.pdf. Diakses 3 Juli 2018 pukul 14:52. 
10. Sisvana D. Faktor-Faktor yang Berhubungan dengan Motivasi Kerja Pegawai Tetap di Rumah Sakit Umum Daerah Kabupaten Penajam Paser Utara Kalimantan Timur Tahun 2014. Jurnal Administrasi Rumah Sakit. 2016. 2(2):139-149.
11. Aswat B. Faktor-Faktor Yang Berhubungan Dengan Motivasi Kerja Perawat Di Unit Rawat Inap Rsud Puri Husada Tembilahan Kabupaten Inderagiri Hilir Riau Tahun 2010. Tesis Program Pascasarjana Universitas Indonesia. 2010. 